\title{
Mentira, erro, ilusão, falsidade. Sobre Nietzsche e Wittgenstein
}

\author{
Marcelo Carvalho*
}

\begin{abstract}
Resumo: Os trabalhos de Nietzsche e Wittgenstein apresentam contatos e possibilidades de aproximação que se revelam bastante fecundas para a interpretação de ambos. Apresenta-se aqui uma destas possibilidades, explicitando o terreno no qual ambos os autores situam o debate sobre a verdade e sua relação com a linguagem. Para isto, é feita uma breve apresentação de Sobre a verdade e a mentira em um sentido extra-moral, de Nietzsche, e se procura explicitar sua relação com a concepção de linguagem de Wittgenstein nas Investigações Filosóficas e em Sobre a Certeza.
\end{abstract}

Palavras-chave: Wittgenstein - Nietzsche - verdade

Ainda que pouco usual, a aproximação entre os trabalhos de Nietzsche e Wittgenstein se revela surpreendentemente fecunda, antes de mais nada pela diversidade de meios pelas quais se pode realizá-las. Em primeiro lugar, porque Wittgenstein foi um leitor de Nietzsche e se refere a ele inúmeras vezes em seus manuscritos. Mais do que essa referência direta, entretanto, ambos têm seus trabalhos iniciais fortemente marcados pela influência de Schopenhauer e, de maneira menos explicitada, mas decisiva, de Kant. E, para além dessa origem comum, ambos identificam em Platão e no Sócrates platônico um adversário central no debate a que se propõem. Wittgenstein, a respeito de quem esta oposição é certamente menos conhecida, chega a dizer, em um registro do início dos anos 1930,

\footnotetext{
* Professor da Universidade Federal de São Paulo (UNIFESP), São Paulo, SP, Brasil. E-mail: carvalho.marcelo@uol.com.br.
} 
que "não poderia descrever melhor meu ponto de vista do que afirmando ser ele o oposto daquele representado por Sócrates nos diálogos platônicos"l.

Também a recepção da obra de Nietzsche e do "segundo Wittgenstein" guardam semelhanças, seja por sua eventual aproximação com certo relativismo, seja pela referência ao perspectivismo, seja, por fim, curiosamente, pela relação que mantêm com o relativismo linguístico em antropologia (na medida em que ambos são apropriados como referências teóricas nesse debate).

De uma perspectiva distinta, ambos também mantêm uma relação, por assim dizer, ambígua e complexa com o positivismo e se reconhecem situados em meio a uma cultura alemã em decadência (muitas das referências de Wittgenstein a Nietzsche se situam justamente no contexto desse debate e no reconhecimento da relevância dos trabalhos de Nietzsche a este respeito).

A pluralidade de perspectivas sob as quais se dá essa aproximação evidencia, de maneira inequívoca, para além das diferentes tradições associadas a cada um deles e da diferença no vocabulário e nas referências imediatas de seus textos, a pertinência de uma leitura que confronte essas duas obras.

O que se proporá aqui é um recorte nesse conjunto de possibilidades. Wittgenstein nos oferece o mote para isto quando fala, em um texto de 1938, do sentido em que o conjunto de sua obra poderia ser visto como uma "aproximação de Nietzsche":

Se eu não pretendo apresentar um pensamento mais correto, mas uma outra perspectiva de pensamento, então meu propósito é uma "transvaloração dos valores", e eu me aproximo de Nietzsche, e, também, desta maneira, de que, na minha opinião, o filósofo deve ser um poeta ${ }^{2}$.

1 "Ich kann meinen Standpunkt nicht besser charakterisieren, als indem ich sage, dass er der entgegengesetzte Standpunkt dessen ist, welchen Sokrates in den platonischen Dialogen vertritt". WITTGENSTEIN, L. Wittgenstein's Nachlass: The Bergen Electronic Edition, TS 302, p. 14.

2 "Wenn ich nicht ein richtigeres Denken, sondern eine [andere| neue] Gedankenbewegung 
Nossa investigação pretenderá tematizar essa aproximação de Wittgenstein em relação a Nietzsche e argumentar que, de uma maneira talvez não suspeitada por Wittgenstein, seu trabalho se constitui como herdeiro de uma ruptura que encontra em Nietzsche seu momento central. Trata-se de explicitar a aproximação entre ambos na identificação "disto" que é o oposto à verdade: nem o não-ser, nem a falsidade, nem o erro, nem a ilusão, mas a mentira em um sentido extra-moral.

Em outros termos, trata-se de mostrar que Nietzsche, em textos como Sobre verdade e mentira no sentido extra-moral e Genealogia da moral (mas não apenas neles) promove um deslocamento do debate sobre verdade e significação que se reencontra na base do projeto das Investigações Filosóficas de Wittgenstein. Encontramos na obra de Nietzsche a explicitação de um novo terreno no qual se situaria o debate sobre a verdade, e é sobre este mesmo terreno que Wittgenstein assentaria o projeto de sua filosofia madura.

Para que compreendamos o deslocamento realizado por Nietzsche, consideremos brevemente seu principal interlocutor: o projeto lógico de Platão. Uma perspectiva interessante a partir da qual podemos descrever o platonismo é a maneira como ele estabelece o conceito de falsidade como o oposto da verdade, esvaziando o conceito de verdade de qualquer sentido ontológico. O paradoxo que é situado na base da construção, no Sofista, deste conceito lógico de verdade pode ser descrito como resultante da dificuldade de que, na medida em que se identifique a verdade ao ser, dando a ela sentido ontológico, seu oposto, o "falso", referiria ao não-ser,

lehren will, so ist mein Zweck eine 'Umwertung von Werten' und ich komme auf Nietzsche, sowie auch dadurch, daß meiner Ansicht nach, der Philosoph ein Dichter sein sollte", WITTGENSTEIN, L. Wittgenstein's Nachlass: The Bergen Electronic Edition, MS142, 145r. 
de tal maneira que, na medida em que não se pode dizer o não-ser (de Parmênides), todo discurso seria ou verdadeiro, ou simplesmente sem sentido, não sendo possível o discurso falso. Em contrapartida, é o esvaziamento de qualquer sentido ontológico associado ao conceito de verdade que possibilitará a compreensão do discurso falso como alteridade e a eliminação do paradoxo. $\mathrm{O}$ conceito de verdade passa a ser concebido como a descrição de uma relação (lógica) entre a linguagem e mundo, definida para a tradição nos termos do livro IV da Metafísica de Aristóteles: dizer que é aquilo que é, e dizer que não é aquilo que não é, é dizer o verdadeiro. A verdade aparece, nessa concepção, não como uma característica das próprias coisas, nem como uma característica exclusiva da linguagem, referida a si própria (como concebido por alguns sofistas), mas como uma relação de adequação entre linguagem e mundo. $\mathrm{O}$ oposto da verdade é a falsidade: é dizer algo diferente daquilo que é (ou seja, dizer que é aquilo que não é, e dizer que não é aquilo que é).

É a essa concepção de verdade que Nietzsche se contrapõe explicitamente a partir de Sobre verdade e mentira. Mas não apenas a ela. Recusa-se ali também a contraposição cartesiana entre verdade e erro, que, da perspectiva da construção do conhecimento, associa o conceito de verdade a um conteúdo epistemológico. E recusa, ainda, a concepção kantiana de ilusão, resultado do projeto de delimitação da razão na Crítica da Razão Pura, que Kant contrapõe à verdade na dialética transcendental.

Nietzsche situa o debate sobre a verdade em um outro terreno: ainda se trata de um conceito que opera no domínio da linguagem, e, em certo sentido, esvaziado de conteúdo ontológico e epistemológico, mas que se contrapõe à mentira, em uma perspectiva extra-moral. $\mathrm{O}$ debate sobre a verdade é situado em meio à constituição da linguagem, em meio às relações humanas, às "ações" e aos interesses humanos. 
A contraposição de Nietzsche a essa concepção se explicita de forma clara nesse texto de 1873, Sobre verdade e mentira no sentido extra-moral, mas o núcleo da concepção encontrada ali se encontra também em sua obra tardia. Consideremos de maneira mais detida a explicação do processo de constituição de conceitos apresentada neste fragmento de 1873. Nietzsche descreve a delimitação conceitual por meio da "igualação do não-igual". Uma palavra se torna conceito justamente por distanciar-se da vivência primitiva à qual estava inicialmente associada, e por passar a nomear "um sem número de casos, mais ou menos semelhantes", e, portanto, desiguais ${ }^{3}$.

O que se explicita aqui é que o conceito resulta de um processo de construção, e que este processo não responde a essências ou a qualquer unidade exterior, dada preliminarmente, de tal maneira que sua determinação envolve arbitrariedade. Nada, em nossas "vivências primitivas", determina a constituição de conceitos ou os limites que eles devem assumir. Nietzsche desenvolve seu comentário apresentando dois exemplos. $\mathrm{O}$ primeiro deles nos remete implicitamente a Platão e, de um modo mais imediato, a Goethe, em sua análise da metamorfose das plantas $^{4}$, na qual concebe a unidade dos conceitos da botânica a partir da referência a uma planta primordial, e às leis da metamorfose por meio das quais se

3 "Pensemos ainda, em particular, na formação dos conceitos. Toda palavra torna-se logo conceito justamente quando não deve servir, como recordação, para a vivência primitiva, completamente individualizada e única, à qual deve seu surgimento, mas ao mesmo tempo tem de convir a um sem número de casos, mais ou menos semelhantes, isto é, tomados rigorosamente, nunca iguais, portanto, a casos claramente desiguais. Todo conceito nasce por igualação do não-igual” (WL/VM 1, KSA 1.879).

4 Cf. e.g. Goethe, Italienische Reise, Palermo, 17 de abril de 1787: "Perante tantas formações novas e variadas, veio-me a antiga mania de saber se entre esta multidão não poderia descobrir a planta originária [Urpflanze]. Ora, porque uma planta dessas tem de existir! Como poderia reconhecer que esta ou aquela formação é uma planta, se não tivessem sido todas formadas de acordo com um modelo?". 
constituiriam as plantas que se apresentam efetivamente para nós. Em contraposição a Goethe, Nietzsche explicita a arbitrariedade desse processo de abandono da particularidade:

Assim como é certo que nunca uma folha é inteiramente igual a uma outra, é certo que o conceito de folha é formado por arbitrário abandono dessas diferenças individuais, por um esquecer-se do que é distintivo, e desperta então a representação, como se na natureza além das folhas houvesse algo, que fosse "folha", uma espécie de folha primordial, segundo a qual todas as folhas fossem tecidas, desenhadas, recortadas, coloridas, frisadas, pintadas, mas por mãos inábeis, de tal modo que nenhum exemplar tivesse saído correto e fidedigno como cópia fiel da forma primordial (WL/VM 1, KSA 1.880).

De maneira análoga é feita a descrição da constituição do conceito de honestidade:

O certo é que não sabemos nada de uma qualidade essencial, que se chamasse "a honestidade", mas sabemos, isso sim, de numerosas ações individualizadas, portanto desiguais, que igualamos pelo abandono do desigual e designamos, agora, como ações honestas; por fim, formulamos a partir delas uma qualitas occulta com o nome: "a honestidade" (idem).

Para além da objeção à inversão platônica, que coloca a honestidade na origem das ações honestas, e de uma afirmação da prioridade (ontológica e epistemológica) do particular, o que (como em Wittgenstein) talvez ecoe uma influência do romantismo ${ }^{5}$, trata-se de observar que se explicita aqui a recusa de qualquer essência

5 Cf. WL/VM 1, KSA 1.880: "A desconsideração do individual e efetivo nos dá o conceito, assim como nos dá também a forma, enquanto que a natureza não conhece formas nem conceitos, portanto também não conhece espécies, mas somente um X, para nós inacessível e indefinível. Pois mesmo nossa oposição entre indivíduo e espécie é antropomórfica e não provém da essência das coisas, mesmo se não ousamos dizer que não lhe corresponde: isto seria, com efeito, uma afirmação dogmática e como tal tão indemonstrável quanto seu contrário".

204 I Cad. Nietzsche, São Paulo, n. 33, p. 199-214, 2013. 
referida pelos conceitos, e que a unidade a ele associada é construída a partir de um outro critério que não o ajuste à objetividade, a algo "exteriormente" dado como "objeto".

$O$ esquecimento do processo que se situa na origem da constituição do conceito, entretanto, faz com que a intrincada rede de conceitos, o "domo conceitual" fragilmente erigido pelos próprios homens, se apresente a eles como objetividade a partir da qual compreendem as suas ações e nossas experiências. Também essa formulação do argumento não é nova no debate alemão do séc. XIX, seja na tradição kantiana, seja no contexto da herança hegeliana.

Esse pano de fundo contextualiza a apresentação uma concepção da verdade ainda concebida no domínio da linguagem, a qual, entretanto, não se apresenta mais como um ajuste da linguagem a uma objetividade dada independentemente dela:

O que é a verdade, portanto? Um batalhão móvel de metáforas, metonímias, antropomorfismos, enfim, uma soma de relações humanas, que foram enfatizadas poética e retoricamente, transpostas, enfeitadas, e que, após longo uso, parecem a um povo sólidas, canônicas e obrigatórias ${ }^{6}$.

A compreensão dessa caracterização pressupõe a explicitação do desdobramento da caracterização da "arbitrariedade" da construção conceitual identificada por Nietzsche, e, com isto, da novidade do contexto em que situa o debate já neste texto de juventude: a contrapartida do reconhecimento de que a linguagem, e, de modo mais específico, os conceitos, não referem a essências realmente existentes, e de que eles se constituem, portanto, movidos por outras forças, coloca como questão a explicitação de $a$ quê respondem conceitos e linguagem em geral.

6 Cf. VL/VM 1, KSA 1.880: “As verdades são ilusões, das quais se esqueceu que o são, metáforas que se tomaram gastas e sem força sensível, moedas que perderam sua efígie e agora só entram em consideração como metal, não mais como moedas". 
Não é logicamente que ocorre a gênese da linguagem, e o material inteiro, no qual e com o qual mais tarde o homem da verdade, o pesquisador, o filósofo, trabalha e constrói, provém, se não de Cucolândia das Nuvens, em todo caso não da essência das coisas.

O conceito de verdade, na medida em que se apresenta em meio ao discurso, pressupõe a linguagem. E a construção da linguagem não se dá em resposta às próprias coisas: não se trata de ajustar nossos conceitos ao ser, ou de estruturar a linguagem segundo uma ontologia dada, para que por meio dela se possa dizer o que é. A explicitação da arbitrariedade desta construção implica que ela responda, acima de tudo, a um interesse humano, móvel, circunstancial e variável, e que, portanto, só se poderá falar de verdade a partir desse interesse, que aparece para nós como algo "sólido, canônico e obrigatório".

Não se trata de fazer aqui um percurso mais amplo pela obra de Nietzsche, mas, de qualquer forma, esta concepção da relação entre a construção conceitual e os interesses e relações humanas parecem permanecer em seus trabalhos posteriores e se apresentar, por exemplo, como um pressuposto à investigação da Genealogia da moral, contrapartida de sua recusa da questão platônica pelo significado e pela essência.

Esse percurso nos conduz, assim, à explicitação de que a constituição dos conceitos e da linguagem em geral não responde à necessidade, não responde a um critério de adequação ao mundo, às essências, às próprias coisas. Em sua base se encontra, então, o arbítrio. E se coloca como questão identificar os elementos que, nesse novo contexto, conduzem a arbitrariedade dessa escolha: a quê a linguagem responde, e, então, a quê a verdade, que se apresentará no contexto dessa linguagem, refere. É para este mesmo contexto de debates que caminha a construção da obra de Wittgenstein. 
O percurso de Wittgenstein, do Tractatus, publicado em 1921, às Investigações Filosóficas, escritas entre 1936 e 1946, e publicadas postumamente em 1953, pode ser descrito como a passagem da afirmação à recusa do conceito platônico de verdade (lógica). Ou, então, como o processo de construção de uma concepção da "independência da gramática", segundo a expressão usada por Wittgenstein em meados dos anos 1930, em que se abandona qualquer possibilidade de determinação da significação e da estrutura da linguagem a partir de uma objetividade que lhe seja exterior. Em meio a este percurso, observamos não apenas a recusa de que a linguagem remete a fatos e objetos, mas também de que seja possível concebê-la como uma nomeação de percepções e fenômenos que se apresentassem para nós de forma imediata (e, portanto, de remeter a linguagem a uma fenomenologia). Trata-se de recusar "objetividade" à linguagem, seja em sentido transcendental, seja em sentido fenomênico, o que não resultará, entretanto, no abandono da própria idéia de objetividade no interior da linguagem.

Assim, nas Investigações Filosóficas, entre os parágrafos 1 e 88, trecho originado de um manuscrito escrito em 1936, se apresenta uma cerrada contraposição à imagem da linguagem identificada na citação de Agostinho que abre o texto, caracterizada justamente pela suposição de que cada palavra tem um significado, de que o significado está relacionado à palavra, e de que o significado é o objeto que a palavra substitui. Cada uma dessas afirmações será objeto de objeções nesse trecho inicial do livro. Trata-se, de uma perspectiva mais ampla, de se contrapor à própria suposição de que a pergunta pelo significado seja adequada e pertinente. Palavras não significam objetos, como se supõe habitualmente, ainda que uma relação entre palavras e objetos possa ser, eventualmente, construída. Também não têm seu significado dado por imagens mentais, ou conjuntos definidos de maneira extensional, ou mesmo por regras. Todo este conjunto de concepções, relacionadas entre 
si e associadas, em última instância, à “imagem agostiniana da linguagem", à suposição de que palavras nomeiam objetos, compartilham o equívoco de supor que a linguagem opera de maneira "teórica", como uma correlação de significações (entre o mundo e a linguagem, situada fora do mundo). A isto Wittgenstein contrapõe a descrição de como procedemos com a linguagem, de como usamos as palavras, de nossas ações e da linguagem compreendida como parte desse contexto, no qual a pergunta pelo significado se revela, em geral, irrelevante, e o que é pertinente é a descrição dos usos que fazemos das palavras, do que fazemos com elas.

Entre os parágrafos 65 e 80 do livro são debatidas as suposições de que conceitos significam essências ou algo equivalente a isto, e de que eles (os conceitos) têm limites claros. O núcleo da concepção aqui apresentada é bastante próximo daquele que encontramos em Sobre Verdade e Mentira, de Nietzsche. Ele se inicia com uma passagem bastante conhecida, em que Wittgenstein recusa que exista algo comum a tudo aquilo a que se chama de linguagem:

Em vez de indicar algo que é comum a tudo aquilo que chamamos de linguagem, digo que não há uma coisa comum a esses fenômenos, em virtude da qual empregamos para todos a mesma palavra, - mas sim que estão aparentados uns com os outros de muitos modos diferentes. E por causa desse parentesco ou desses parentescos, chamamo-los todos de "linguagens"?

Só se encontraria no conjunto de coisas agregadas sob um conceito (neste caso específico, o conceito de "linguagem") uma certa "semelhança de família", uma série de sobreposições e similaridades que se entrecruzam. A argumentação se estrutura por dois caminhos distintos. De um lado, trata-se de evidenciar que o nome não remete a nenhum objeto por ele significado, nem a qualquer

7 WITTGENSTEIN, L. Investigações Filosóficas, § 65. 
correlato ou substituto deste "objeto" (definição extensional, essência, esquema, regra, imagem, etc). De outro, de explicitar que não apenas não há objeto referido, mas também não há uma unidade claramente delimitada, rígida, no uso que se faz de um conceito. Nesse contexto, é importante frisar que a concepção de semelhança de família não pode ser "naturalizada": não se deve supor que esta indicação de uma "semelhança" nos remete a algo marcado nas próprias coisas. Ela se constitui apenas em meio às circunstâncias e a intenções presentes em nossos usos e na maneira como lidamos com nossos exemplos ${ }^{8}$. E ela também não permite uma delimitação rígida dos usos de um conceito.

Também Wittgenstein explicita sua concepção comentando o conceito de "folha", e também aqui parece tratar-se de uma referência a Goethe. O problema por detrás do comentário é justamente a dificuldade de se conceber a significação do conceito sem a fixação de sua unidade, seja por referência a uma essência, àquilo que é comum a todas as folhas, ou mesmo a uma delimitação extensional. Em lugar de uma unidade dada externamente, o que temos é uma unidade fixada pela forma como usamos o conceito, em sua aplicação.

Se me mostrarem diferentes folhas e me disserem: "isto chama-se 'folha", então adquiro um conceito da forma de folha, uma imagem dela no espírito. - mas que aspecto tem, pois, a imagem de uma folha que não mostra uma folha determinada, mas sim "o que é comum a todas as formas de folhas"? Que tom de cor tem o "modelo no meu espírito" da cor verde - daquilo que é comum a todos os tons de verde?

O que o argumento explicita até aqui é a dificuldade envolvida na compreensão de como se apresenta uma idéia geral de folha, e de sua relação com os casos particulares. $\mathrm{O}$ argumento segue:

8 WITTGENSTEIN, L. Investigações Filosóficas, §71. 
"Mas não poderia haver tal modelo 'geral'? Algo como um esquema de folha, ou um modelo de verde puro?" - Certamente! Mas que esse esquema seja compreendido como esquema, e não como forma de uma folha determinada, e que um quadrinho de verde puro seja compreendido como modelo de tudo aquilo que tenha a cor verde e não como modelo para o verde puro - isto depende do modo como esses modelos são usados? .

O ponto central desta passagem do texto consiste em indicar que a própria suposição de que se tem um modelo ou esquema de "folha" não é dada como um objeto de natureza especial. O modelo de uma folha é, ele próprio, uma folha, e o que o torna um modelo é o uso que se faz disto que, em outras circunstâncias, seria um objeto ordinário.

Nos termos do que foi dito anteriormente, também para Wittgenstein o conceito aparece como uma agregação de particulares que não responde à "objetividade", e que, nestes termos, nunca deixa de ser "arbitrária" e imprecisa - na medida em que se possa falar de precisão, pois conceitos como estes não são super-conceitos: eles operam, e são "imprecisos" como todos os outros.

Assim, para além das significativas diferenças no percurso e nos objetivos de suas investigações, Wittgenstein, como Nietzsche, é colocado frente ao problema de indicar a quê o processo de constituição da significação e da linguagem responde, na medida em que recusa que esta seja dada por referência a uma objetividade que lhe seria anterior. E a resposta de Wittgenstein nos remete a uma releitura de Nietzsche e à pergunta pelo sentido daquela aproximação a que ele se referia na anotação de 1938. Segundo as Investigações, imaginar uma linguagem é imaginar uma forma de vida $^{10}$. É esta referência às formas de vida (pouco trabalhada nas

9 Ibid., $\$ 73$.

10 WITTGENSTEIN, L. Investigações Filosóficas, §19; cf. também §§ 23 e 241. 
Investigações) que desempenha o papel de determinação última do processo de constituição da significação e da linguagem. Nos termos da Parte II das Investigações, "O que deve ser aceito, o dado, são - pode-se dizer - formas de vida" "

Mas o percurso das Investigações se propõe a uma radicalização da recusa da imagem agostiniana da linguagem em suas mais diversas formas, e a uma explicitação do que se faz acompanhar dessa recusa.

Em seus últimos manuscritos Wittgenstein apresenta de maneira mais explícita o que compreende com esta afirmação de que o dado é uma forma de vida. Nos textos publicados sob o título de Sobre a Certeza se apresenta a linguagem como um sistema em meio ao qual o conceito de fundamento opera de maneira muito particular, na medida em que as proposições se sustentam mutuamente. Não se concebe que existam proposições básicas, justificadas a partir da experiência ou de percepções sensíveis, ou evidentes por qualquer referência a algo exterior à linguagem. Nas palavras de Wittgenstein, "usamos juízos como princípios para a formulação de juizos"'12, e não há um grau zero em que a linguagem refere a algo exterior a ela própria.

Como se determina, então, aquilo que se apresentará para nós como um sistema de linguagem, ou aquilo que se suporá ser verdadeiro, ou, mais do que simplesmente verdadeiro, o que se apresentará como evidente e necessário? O processo de justificação chega a um fim:

11 Ibid., II §345.

12 Id., Sobre a Certeza, §124.

Cad. Nietzsche, São Paulo, n. 33, p. 199-214, 2013. 
o fim não é o fato de certas proposições se nos apresentarem como sendo verdadeiras, isto é, não se trata de uma espécie de ver da nossa

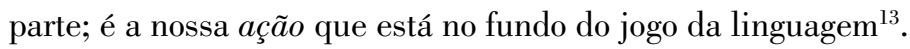

O que se apresenta como verdadeiro no final de nossa cadeia de justificações não são proposições que remetem a um imediato, ou à objetividade das coisas, mas uma forma particular de agir e de julgar. A estrutura da linguagem remete a nossas ações, às relações humanas, que desempenham o papel de grau último dessa cadeia de argumentos, e que define aquilo que, de maneira transitória, será considerado o mais sólido e certo, tão certo que nem se apresenta para nós como uma certeza: é simplesmente assim que fazemos. O fim da cadeia das razões é a ação, sem justificativa, pois já não cabe falar de justificação ("A dificuldade é compreender a falta de fundamento das nossas convicções"14).

Na base da constituição desse sistema de linguagem, dos juízos a partir dos quais emitimos juízos, se encontra, então, uma ação sobre a qual não cabe falar de justificação: "o fim não é um pressuposto não fundamentado: é uma via de ação não fundamentada" $"$.

Será, então, apenas no interior de um sistema de linguagem que se poderá falar de verdade. A verdade se diz no contexto de uma linguagem, que, por sua vez, é uma forma de vida, e a respeito dessa própria linguagem, ou fora de uma linguagem qualquer, não cabe falar de verdade ou falsidade. A objeção se apresenta de imediato, e é formulada no interior do próprio texto de Wittgenstein: "Mas então não há nenhuma verdade objetiva? Não é verdadeiro nem falso que alguém tenha estado na Lua?"16.

E a resposta nos repede essa dependência que a afirmação de algo como verdadeiro tem com uma linguagem particular, e,

13 WITTGENSTEIN, L. Sobre a Certeza, §204.

14 Ibid., §166.

15 Ibid., §124 (itálicos acrescentados).

16 Ibid., §108. 
portanto, com uma forma de vida particular: "Se estamos a pensar dentro do nosso sistema (Wenn wir in unserm System denken), então é certo que nunca ninguém esteve na Lua"17.

A "gramática", em meio à qual a verdade se coloca, é autônoma em relação à objetividade da "coisa em si", mas não em relação às formas de vida - e aos interesses humanos (ainda que estes precisem de aspas, pois não se deve cometer o equívoco de produzir uma naturalização desse conceito de "interesse").

$\mathrm{Na}$ base da constituição da linguagem, e como pressuposto a toda significação, e à própria experiência, encontramos, então, uma prática que "deve cuidar de si própria", uma ação instauradora que não responde a nada senão a si própria.

Esse terreno no qual encontramos, na obra tardia de Wittgenstein, o debate sobre a verdade: não o terreno lógico delimitado por Platão, e não a epistemologia cartesiana, ou a investigação transcendental kantiana, mas algo que precederia e determinaria a própria constituição da linguagem, em meio à qual se pode falar de verdade, se revela, então, pouco distante daquele delimitado em Sobre a Verdade e a Mentira. Neste contexto de ações, formas de vida, interesses, ou qualquer outro conceito com o qual tentemos apreender esta (vida) inominada que precede a nomeação e que precede a própria experiência, não é possível, ainda, falar de falsidade, e o oposto daquilo que se põe como verdadeiro é uma outra forma de vida, um outro interesse, em um contexto anterior à moral. De tal maneira que a filosofia tardia de Wittgenstein se apresenta, da perspectiva desta compreensão do processo de constituição da linguagem e do conceito de verdade, como uma contínua aproximação com Nietzsche.

17 Ibid., §108 (itálicos acrescentados). 
Abstract: The works of Nietzsche and Wittgenstein present very fruitful possibilities of contacts and connection that unfold interesting for the interpretation of both. We present here one of these possibilities, considering the ground on which both authors situate the debate about truth and its relationship to language. To do this we make a brief presentation of Nietzsche's On truth and lie in an non moral sense and try to clarify its relationship with the concept of language presented in Wittgenstein's Philosophical Investigations and On Certainty.

Keywords: Wittgenstein - Nietzsche - Truth

\section{referências bibliográficas}

1. GOETHE, J. W. Italienische Reise. Berlim: Fischer Taschenbuch, 2009.

2. . Viagem à Itália. São Paulo: Companhia das Letras, 1999.

3. NIETZSCHE, F. Sämtliche Werke. Kritische Studienausgabe. Giorgio Colli/Mazzino Montinari (eds.). Munchen/Berlin: DTV/Walter de Gruyter, 1980, 15v.

4. . Obras incompletas. Trad. Rubens Rodrigues Torres Filho. São Paulo: Nova Cultural, 1987, 2v. (Col. "Os pensadores").

5. WITTGEnSTEIN, L. Investigações Filosóficas. Trad. José Carlos Bruni. São Paulo: Abril Cultural, 1975 (Coleção "Os Pensadores").

6. On Certainty. Ed. G. E. M. Anscombe and G. H. von Wright, trans. D. Paul and G. E. M. Anscombe. Oxford: Blackwell, 1974.

7. Philosophische Untersuchungen, Philosophical Investigations. 4nd ed., Oxford: Blackwell, 2009.

8. __ Philosophische Untersuchungen: Kritisch-genetische Edition. Ed. J. Schulte in collaboration with H. Nyman, E. von Savigny and G. H. von Wright. Frankfurt am Main: Suhrkamp, 2001.

9. __ Wittgenstein's Nachlass: The Bergen Electronic Edition, ed. Wittgenstein Archives at the University of Bergen. Oxford: OUP, 2000.

Artigo recebido para publicação em 15/09/2012.

Artigo aceito para publicação em 25/10/2012.

214 | Cad. Nietzsche, São Paulo, n. 33, p. 199-214, 2013. 